\title{
Treatment of melasma in Caucasian patients using a novel 694-nm Q-switched ruby fractional laser
}

Said Hilton ${ }^{1 *}$, Heike Heise ${ }^{1}$, Bettina Alexandra Buhren ${ }^{2}$, Holger Schrumpf ${ }^{2}$, Edwin Bölke ${ }^{3}$ and Peter Arne Gerber ${ }^{2 *}$

\begin{abstract}
Background: Melasma is a common hypermelanosis of the face. The use of a classical Q-switched ruby laser (QSRL) to treat melasma is discussed controversially and is associated with frequent adverse effects, such as hyper- or hypopigmentation. Recently a fractional-mode (FRx) QSRL was developed to minimize the adverse effects of classical QSRL. The objective of this research was to evaluate the efficacy and safety of a novel FRx-QSRL in the treatment of melasma in Caucasian patients.
\end{abstract}

Methods: We performed a retrospective study of 25 Caucasian melasma patients (Fitzpatrick skin types I to III). Patients received one to three FRx-QSRL treatments (Tattoostar FRx, Asclepion Laser Technologies, Jena, Germany) at pulse energies of 4 to $8 \mathrm{~J} / \mathrm{cm}^{2}$. Three blinded investigators independently evaluated the melasma area and severity index (MASI) score before treatment and at the four-to six-week follow-ups. At additional three-month follow-ups, patients evaluated subjective improvement, pain and over-all satisfaction with the treatment according to a numeric analogue score (NAS). Side effects were documented.

Results: At four to six weeks post laser treatment for a mean of 1.4 sessions, we observed a significant $(P=0.0001)$ reduction of the MASI score from 6.54 to 1.98 (72.3\%). Patients rated the pain of the intervention at a mean 2.46 points $(0=$ no pain; $10=$ maximum pain), the improvement at a mean 5.55 points $(0=$ no improvement; $10=$ maximum improvement) and the overall satisfaction at a mean 4.66 points $(0=$ not satisfied; $10=$ maximum satisfaction). After three months, post-inflammatory hyperpigmentation $(\mathrm{PIH})$ and/or recurring melasma were observed in $7(28 \%)$ and 11 (44\%) patients, respectively.

Conclusion: The 694-nm FRX-QSRL is a safe and effective option for treating melasma in Caucasian patients. Over periods of $>3$ months, PIH and/or recurring melasma may develop at significant rates and may reduce patient satisfaction. Multiple treatment sessions with lower pulse energies and/or a post-interventional therapy with hypopigmenting ointments and UV protection may help to minimize these complications.

\section{Background}

Melasma is a common acquired benign pigmentary disorder that classically manifests as symmetrical hypermelanosis of the face. Most commonly melasma affects women of reproductive age with darker skin types (Fitzpatrick skin types IV and higher) but it may also occur at other ages and in men. Briefly, the Fitzpatrick skin type classification system is based on the color of the skin (type I being the fairest (white) and type VI

\footnotetext{
* Correspondence: info@dr-hilton.de; PeterArne.Gerber@med.uni-duesseldorf.de ${ }^{1}$ Medical Skin Center, Düsseldorf, Germany

Full list of author information is available at the end of the article
}

being the darkest (black)) and its response to UV exposure (pigmentation) [1]. An estimated more than five million people are affected by melasma in the United States of America alone [2]. Melasma has a significant negative impact on a patient's quality of life [3]. Risk factors include ultraviolet (UV) exposure, hormonal alterations (for example, pregnancy or oral contraceptives), thyroid disease and anti-seizure medication. Melasma that is related to pregnancy (or hormonal alterations) is also referred to as chloasma. 
The pathogenesis of melasma has remained largely elusive. Established concepts propose a stimulation of pigment-producing cells (melanocytes) by sex hormones (estrogen and progesterone) and UV irradiation. Recent studies have reported paracrine effects amongst melanocytes, keratinocytes and/or fibroblasts [4-7], and have identified stem cell factor (SCF) and c-kit as pathogenic factors. The authors propose that UV irradiation induces SCF in dermal fibroblasts. Subsequently, the proliferation and melanogenesis of melanocytes is induced via SCF/c-kit-induced signaling [8]. Hypopigmenting topical agents containing hydroquinone, broad-spectrum UV protection and camouflage are considered the current standard of care for treating melasma. Additional therapeutic options include topical retinoic acids (tretinoin), azelaic acid, microdermabrasion, chemical peeling or electromagnetic devices, such as lasers [9-12].

Various laser and light systems, including ruby lasers, Er:YAG lasers, carbon dioxide $\left(\mathrm{CO}_{2}\right)$ lasers and intense pulsed light (IPL), have been evaluated for their efficacy in treating melasma [12-14]. IPL therapy effectively reduced the severity of melasma in a population of 89 Asian women [15]. The use of conventional ablative laser systems (Er:YAG and $\mathrm{CO}_{2}$ ) for treating melasma has been reported to be associated with a significant frequency of postinterventional hyper- as well as hypopigmentation $[16,17]$. The frequency of adverse effects may be limited by using novel fractional laser systems [18]. Notably, several trials studying the effects of Q-switched ruby lasers (QSRLs) have reported controversial results. In 1994, Taylor and Anderson noted that QSRLs were ineffective for treating refractory melasma and postinflammatory hyperpigmentation [19]. A split-face study by Tse et al. demonstrated that melasma patients developed post-inflammatory hyperpigmentation (PIH) and worsening of the melasma after QSRL therapy [20]. Conversely, a recent study by Jang et al. reported that a novel fractional-mode (FRx) QSRL (Tattoostar FRx, Asclepion Laser Technologies, Jena, Germany) may be effective in treating melasma in Korean patients [21].

Fractional photothermolysis has revolutionized laser resurfacing (LSR) and was initially presented by Manstein and coworkers in 2004 [22]. The significant adverse effects of classical LSR are significantly reduced by delivering the laser beam using a microarray. This technique creates microscopic columns of treated tissue and intervening areas of untreated skin, thereby allowing rapid re-epithelialization and minimal downtime. Fractional delivery has been developed for $\mathrm{CO}_{2}$, Er:YAG, and yttrium scandium gallium garnet lasers [23]. Recently, a fractional-mode QSRL has been developed (Tattoostar FRx, Asclepion Laser Technologies, Jena, Germany), which can homogeneously deliver ruby laser microspots. The laser delivers a $7.1 \times 7.1 \mathrm{~mm}^{2}$ array of 196 microspots of $300 \mu \mathrm{m}$ at a pulse duration of $40 \mathrm{~ns}$, with an overall coverage of $27.7 \%$. This approach may minimize the adverse effects of classical QSRL, such as $\mathrm{PIH}$ and hypopigmentation. Here, we present a retrospective analysis of 25 Caucasian patients, which assesses the efficacy of an FRx-QSRL in treating melasma.

\section{Methods \\ Patients}

In the study, 25 Caucasian women (mean age 39.8 years; range 31 to 57; Fitzpatrick skin types I to III) with melasma were treated with an FRx-QSRL (Tattoostar FRx, Asclepion Laser Technologies, Jena, Germany) at the Medical Skin Center, Düsseldorf, in 2010 and 2011. Patients presented with epidermal or mixed-type melasma. Of the patients, 19 had had melasma $<10$ years and 6 had had it $>10$ years. The melasma areas were located on the forehead $(n=14)$, the cheeks $(n=12)$, the chin $(n=2)$ or the upper lip $(n=2)$. Identified risk factors included past pregnancies $(n=5)$, hormonal therapy $(n=12)$ and UV exposure $(n=25)$. Some patients presented with melasma in multiple locations and/or risk factors.

\section{Treatment}

We used a 694-nm FRx-QSRL (Tattoostar FRx, Asclepion Laser Technologies, Jena, Germany) at fluences of 4 to $8 \mathrm{~J} / \mathrm{cm}^{2}$ and a frequency of $1 \mathrm{~Hz}$. For each individual patient, the fluence was gradually increased to identify the minimal fluence needed to achieve a clinical effect (photosdisruption). Each patient received laser treatment for all affected areas. In pain-sensitive patients, a topical anesthetic (a lidocaine-tetracaine mix) was applied onto the treated areas 30 minutes prior to treatment. However, most patients tolerated the intervention without anesthesia. The laser treatment lasted up to 10 minutes depending on the size and number of treated areas. Post-intervention, cool packs were applied. Patients were advised to use strict UV protection. If more than one treatment was needed, the patient received additional treatments after intervals of four weeks.

\section{Evaluation}

Photographs (Canon EOS 40D digital camera, Tokyo Japan) were taken before therapy and at the four- to sixweek follow-up sessions. Three blinded investigators independently evaluated the melasma area and severity index (MASI) score before treatment and at the four- to six-week follow-ups, as previously described [24]. At the additional three-month follow-ups, patients evaluated subjective improvement, pain and their overall satisfaction with the treatment was determined according to a 

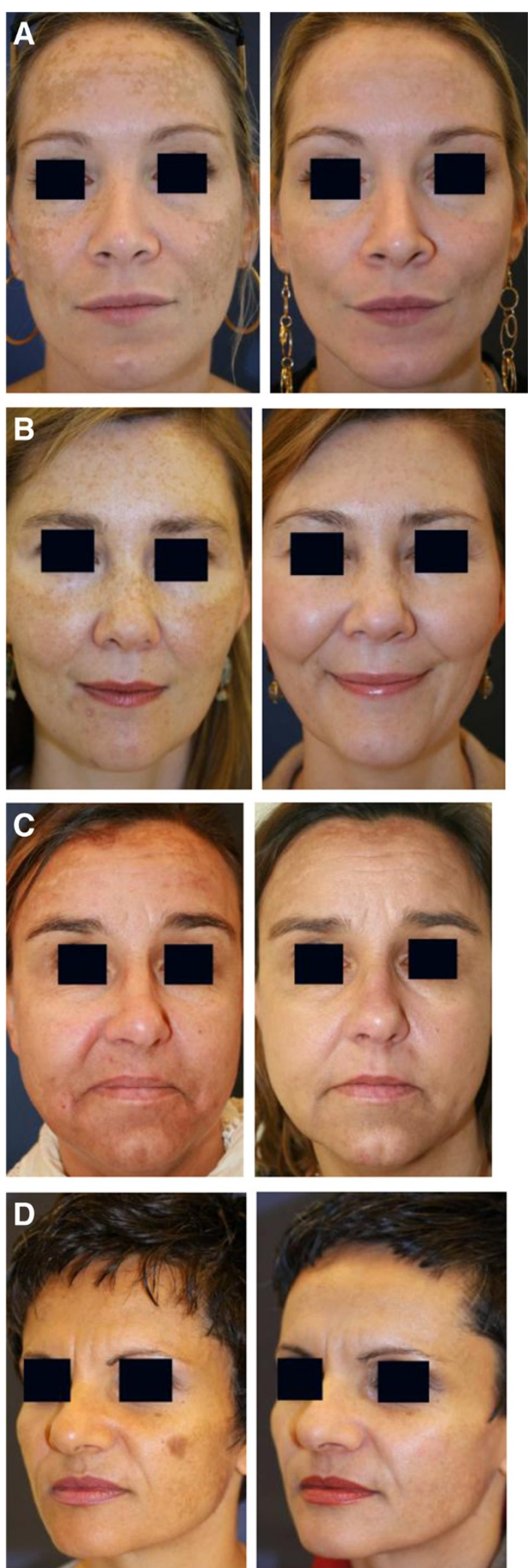

Figure 1 Melasma in Caucasian patients before and four to six weeks after one treatment with the 694-nm FRx-QSRL. (A) 39year old woman, fluence $6 \mathrm{~J} / \mathrm{cm}^{2}$, front: 2 passes, cheeks: 1 pass. (B) 42-year-old woman, fluence $6 \mathrm{~J} / \mathrm{cm}^{2}, 1$ pass. (C) 51-year-old woman, fluence $6 \mathrm{~J} / \mathrm{cm}^{2}, 2$ passes. (D) 42 -year-old woman, fluence $5 \mathrm{~J} / \mathrm{cm}^{2}, 1$ pass. Presented cases are representative examples of the 25 treated patients. FRx, fractional-mode; QSRL, Q-switched ruby laser.

numeric analogue score (NAS). At this time point, side effects were documented.

\section{Statistical analysis}

Student's T-test was used for the statistical analysis, and $P<0.05$ was regarded as statistically significant.

\section{Results}

The analysis included 25 patients. At the follow-up at four to six weeks after the last treatment (there were up to three treatment sessions with a mean of 1.4 sessions) the average MASI score showed a significant reduction from 6.54 to 1.98 (72.3\%) (Figures 1 and 2). In general, the adverse effects for the first days post therapy were mild and included erythema, a burning sensation, pruritus and exfoliation. After three months, PIH and/or recurring melasma were observed in $7(28 \%)$ and $11(44 \%)$ patients, respectively.

The patients' self-evaluation rated the pain of the intervention at a mean 2.46 points $(0=$ no pain; $10=$ maximum pain), the improvement at a mean 5.55 points $(0=$ no improvement; $10=$ maximum improvement $)$ and the overall satisfaction at a mean 4.66 points $(0=$ not satisfied; $10=$ maximum satisfaction). We also used the same protocol to treat patients with darker skin types and melasma and/or PIH, with satisfactory results (Figure 3).

\section{Discussion}

Laser therapy is based on the biophysical principle of selective photothermolysis. The lasers used emit light at a wavelength that is specifically and adequately absorbed by the target chromophores [25]. The target chromophore for pigmented lesions is melanin. Laser light that is adequately absorbed by melanin includes that from ruby $(694 \mathrm{~nm}), \mathrm{Nd}$ :YAG (523 and $1064 \mathrm{~nm}$ ) and alexandrite $(755 \mathrm{~nm})$ lasers. Q-switched (QS) lasers generate a rapid burst of light, which matches the thermal relaxation time for melanin, thereby effectively destroying the pigment [14].

QS-Nd:YAG lasers have been shown to be effective and are widely used in the management of melasma [26-29]. A representative recent study by Zhou et al. of 50 patients (Fitzpatrick skin types IV to VI) demonstrated a mean decrease in the MASI score of $61.3 \%$ after nine sessions. At the three-month follow-up a 


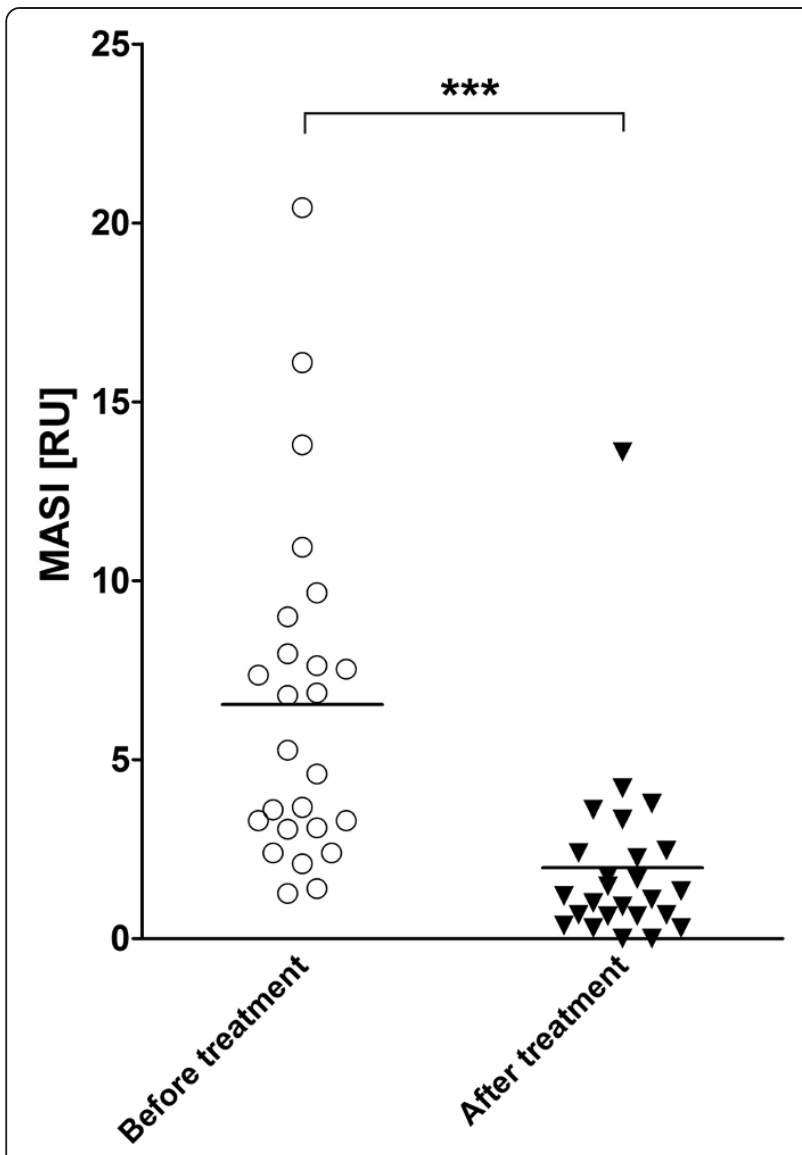

Figure 2 Melasma area and severity index (MASI) scores before and four to six weeks after the final treatment with the 694-nm FRX-QSRL. Values are plotted as individual ratios and mean ratios are shown by the horizontal bar $\left({ }^{* *} P \leq 0.0005\right)$. FRx, fractionalmode; QSRL, Q-switched ruby laser.

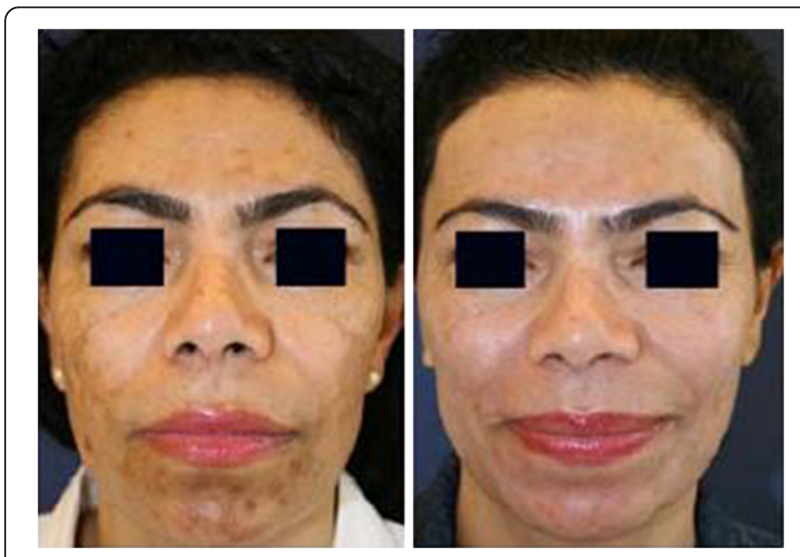

Figure 3 Melasma in an African patient before and 12 weeks after the final treatment with the 694-nm FRx-QSRL. 50-year old woman; first session: fluence $6 \mathrm{~J} / \mathrm{cm}^{2}, 1$ pass; second session: fluence $7 \mathrm{~J} / \mathrm{cm}^{2}, 1$ pass. The patient applied a combination of topical bleaching agents and strict UV protection for the documented 12 post-intervention weeks. FRx, fractional-mode; QSRL, Q-switched ruby laser. recurrence rate of $64 \%$ was noted [29]. A study of 50 patients by Sim et al. reported improvement rates of $50 \%$ to $74 \%$ [28]. For the QSRL, earlier reports state that the laser is ineffective for melasma or may even worsen the pigmentation after therapy $[19,20]$. Conversely, a recent study by Jang et al. demonstrated a mean decrease of the MASI score of $29.8 \%$ in 15 Korean patients after six treatments with an FRx-QSRL (Tattoostar FRx, Asclepion Laser Technologies, Jena, Germany). Two patients reported a slight worsening. None of the patients reported any long-term adverse effects such as PIH [21]. Jang et al. found that a QSRL was more effective for treating melasma compared to a QS-Nd:YAG laser [21]. This has been demonstrated by comparative studies for other pigmented lesions, such as nevus of Ota, lentigo, PIH and Becker's nevus, and it is proposed that this is due to the stronger absorption of the 694-nm wavelength light (QSRL) by melanin compared to 1064-nm wavelength light (QS-Nd: YAG) $[20,21,30]$.

Consistent with the results of Jang et al., we have demonstrated a significant $(P=0.0001)$ decrease of the MASI score of $72.3 \%$ in 25 Caucasian patients after a mean of 1.4 sessions with an FRx-QSRL (Tattoostar FRx, Asclepion Laser Technologies, Jena, Germany). As the risk of common adverse effects of QSRL therapy, such as PIH, is expected to be significantly lower in Caucasian compared to Asian skin types, we applied higher fluences ( 4 to $8 \mathrm{~J} / \mathrm{cm}^{2}$ ) per session compared to Jang et al. (2 to $\left.3 \mathrm{~J} / \mathrm{cm}^{2}\right)$. However, this more aggressive treatment resulted in a significantly higher rate of adverse effects (PIH and/or recurring melasma in $28 \%$ and $44 \%$ of the patients). Lower fluences and multiple treatment sessions may reduce the frequency of these adverse effects. However, many patients refuse further treatment (and want to avoid additional costs) if the result of an initial treatment is minimal. An additional option could be a multimodal therapy using an FRx-QSRL in combination with microdermabrasion [27], chemical peeling [31] and/or hypopigmenting topical agents [32].

\section{Conclusions}

In summary, the FRx-QSRL is a safe and effective treatment for melasma for patients with Caucasian or Asian skin types. Multimodal concepts may further increase the efficacy and reduce the adverse effects of the therapy. We maintained only a three-month follow-up after the final treatment, so further long-term studies are needed.

\section{Consent}

Written informed consent was obtained from the patients for the publication of this report and any accompanying images. 


\section{Abbreviations}

FRx: Fractional-mode; IPL: Intense pulsed light; LSR: Laser resurfacing; MASI: Melasma area and severity index; PIH: Post-inflammatory hyperpigmentation; QS: Q-switched; QSRL: Q-switched ruby laser; SCF: Stem cell factor.

\section{Competing interests}

PA Gerber received honoraria for oral presentations by Asclepion Laser Technologies.

\section{Authors' contributions}

$\mathrm{SH}$ and $\mathrm{HH}$ performed the laser treatments and collected the data. BAB, HS, EB and PAG evaluated and analyzed the data, and wrote the manuscript. Al authors read and approved the final manuscript.

\section{Author details}

${ }^{1}$ Medical Skin Center, Düsseldorf, Germany. ${ }^{2}$ Departments of Dermatology, University of Düsseldorf, Düsseldorf, Germany. ${ }^{3}$ Radiation Oncology, Medical Faculty, University of Düsseldorf, Düsseldorf, Germany.

Received: 11 July 2013 Accepted: 29 October 2013

Published: 14 November 2013

\section{References}

1. Taylor SC, Cook-Bolden F: Defining skin of color. Cutis 2002, 69:435-437.

2. Grimes PE: Melasma. Etiologic and therapeutic considerations. Arch Dermatol 1995, 131:1453-1457.

3. Balkrishnan R, McMichael AJ, Camacho FT, Saltzberg F, Housman TS, Grummer S, Feldman SR, Chren MM: Development and validation of a health-related quality of life instrument for women with melasma. $\mathrm{Br} J$ Dermatol 2003, 149:572-577

4. Imokawa G, Yada Y, Miyagishi M: Endothelins secreted from human keratinocytes are intrinsic mitogens for human melanocytes. J Biol Chem 1992, 267:24675-24680.

5. Imokawa G, Yada Y, Morisaki N, Kimura M: Biological characterization of human fibroblast-derived mitogenic factors for human melanocytes. Biochem J 1998, 330(Pt 3):1235-1239.

6. Kang HY, Choi YM: FK506 increases pigmentation and migration of human melanocytes. Br J Dermatol 2006, 155:1037-1040.

7. Schauer E, Trautinger F, Kock A, Schwarz A, Bhardwaj R, Simon M, Ansel JC, Schwarz T, Luger TA: Proopiomelanocortin-derived peptides are synthesized and released by human keratinocytes. J Clin Invest 1994, 93:2258-2262.

8. Kang HY, Hwang JS, Lee JY, Ahn JH, Kim JY, Lee ES, Kang WH: The dermal stem cell factor and c-kit are overexpressed in melasma. $\mathrm{Br} J$ Dermato 2006, 154:1094-1099.

9. Ball Arefiev KL, Hantash BM: Advances in the treatment of melasma: a review of the recent literature. Dermatol Surg 2012, 38:971-984.

10. Sehgal VN, Verma P, Srivastava G, Aggarwal AK, Verma S: Melasma: treatment strategy. J Cosmet Laser Ther 2011, 13:265-279.

11. Sheth VM, Pandya AG: Melasma: a comprehensive update: part I. J Am Acad Dermatol 2011, 65:689-697. quiz 698.

12. Sheth VM, Pandya AG: Melasma: a comprehensive update: part II. J Am Acad Dermatol 2011, 65:699-714. quiz 715.

13. Alster TS, Lupton JR: Lasers in dermatology. An overview of types and indications. Am J Clin Dermatol 2001, 2:291-303.

14. Polder KD, Landau JM, Vergilis-Kalner IJ, Goldberg LH, Friedman PM, Bruce S: Laser eradication of pigmented lesions: a review. Dermatol Surg 2011, 37:572-595.

15. Li YH, Wu Y, Chen JZ, Gao XH, Liu M, Shu CM, Dong GH, Chen HD: Application of a new intense pulsed light device in the treatment of photoaging skin in Asian patients. Dermatol Surg 2008, 34:1459-1464.

16. Angsuwarangsee $\mathrm{S}$, Polnikorn $\mathrm{N}$ : Combined ultrapulse $\mathrm{CO}_{2}$ laser and Q-switched alexandrite laser compared with Q-switched alexandrite laser alone for refractory melasma: split-face design. Dermato/ Surg 2003, 29:59-64.

17. Manaloto RM, Alster T: Erbium:YAG laser resurfacing for refractory melasma. Dermatol Surg 1999, 25:121-123.

18. Rokhsar CK, Fitzpatrick RE: The treatment of melasma with fractional photothermolysis: a pilot study. Dermatol Surg 2005, 31:1645-1650.
19. Taylor CR, Anderson RR: Ineffective treatment of refractory melasma and postinflammatory hyperpigmentation by Q-switched ruby laser. J Dermatol Surg Oncol 1994, 20:592-597.

20. Tse Y, Levine VJ, McClain SA, Ashinoff R: The removal of cutaneous pigmented lesions with the Q-switched ruby laser and the Q-switched neodymium: yttrium-aluminum-garnet laser. A comparative study. J Dermatol Surg Oncol 1994, 20:795-800.

21. Jang WS, Lee CK, Kim BJ, Kim MN: Efficacy of 694-nm Q-switched ruby fractional laser treatment of melasma in female Korean patients. Dermatol Surg 2011, 37:1133-1140.

22. Manstein D, Herron GS, Sink RK, Tanner H, Anderson RR: Fractional photothermolysis: a new concept for cutaneous remodeling using microscopic patterns of thermal injury. Lasers Surg Med 2004, 34:426-438

23. Alexiades-Armenakas MR, Dover JS, Arndt KA: Fractional laser skin resurfacing. J Drugs Dermatol 2012, 11:1274-1287.

24. Pandya AG, Hynan LS, Bhore R, Riley FC, Guevara IL, Grimes P, Nordlund J J, Rendon M, Taylor S, Gottschalk RW, Agim NG, Ortonne JP: Reliability assessment and validation of the Melasma Area and Severity Index (MASI) and a new modified MASI scoring method. J Am Acad Dermatol 2011, 64:78-83.

25. Anderson RR, Parrish JA: Selective photothermolysis: precise microsurgery by selective absorption of pulsed radiation. Science 1983, 220:524-527.

26. Chan NP, Ho SG, Shek SY, Yeung CK, Chan HH: A case series of facial depigmentation associated with low fluence Q-switched 1,064 nm Nd: YAG laser for skin rejuvenation and melasma. Lasers Surg Med 2010, 42:712-719.

27. Kauvar AN: Successful treatment of melasma using a combination of microdermabrasion and Q-switched Nd:YAG lasers. Lasers Surg Med 2012. 44:117-124.

28. Sim JH, Park YL, Lee JS, Lee SY, Choi WB, Kim HJ, Lee JH: Treatment of melasma by low-fluence $1064 \mathrm{~nm}$ Q-switched Nd:YAG laser. $J$ Dermatolog Treat 2013. epub ahead of print.

29. Zhou X, Gold MH, Lu Z, Li Y: Efficacy and safety of Q-switched 1,064-nm neodymium-doped yttrium aluminum garnet laser treatment of melasma. Dermato/ Surg 2011, 37:962-970.

30. Chang CJ, Kou CS: Comparing the effectiveness of Q-switched ruby laser treatment with that of Q-switched Nd:YAG laser for oculodermal melanosis (Nevus of Ota). J Plast Reconstr Aesthet Surg 2011, 64:339-345.

31. Lee GY, Kim HJ, Whang KK: The effect of combination treatment of the recalcitrant pigmentary disorders with pigmented laser and chemical peeling. Dermatol Surg 2002, 28:1120-1123. discussion 1123.

32. Tourlaki A, Galimberti MG, Pellacani G, Bencini PL: Combination of fractional erbium-glass laser and topical therapy in melasma resistant to triple-combination cream. J Dermatolog Treat 2012. epub ahead of print.

doi:10.1186/2047-783X-18-43

Cite this article as: Hilton et al:: Treatment of melasma in Caucasian patients using a novel 694-nm Q-switched ruby fractional laser. European Journal of Medical Research 2013 18:43.

\section{Submit your next manuscript to BioMed Central and take full advantage of:}

- Convenient online submission

- Thorough peer review

- No space constraints or color figure charges

- Immediate publication on acceptance

- Inclusion in PubMed, CAS, Scopus and Google Scholar

- Research which is freely available for redistribution 